\title{
Optics education in a developing country
}

Enock Jonathan

Enock Jonathan, "Optics education in a developing country," Proc. SPIE 9664, Ninth International Topical Meeting on Education and Training in Optics and Photonics, $96641 Z$ (24 October 2005); doi: 10.1117/12.2207563 and Photonics, 2005, Marseille, France 
Ref ETOP013

\section{Optics education in a developing country Enock JONATHAN}

Applied Physics Department, National University of Science and Technology

PO Box AC939 ASCOT, Bulawayo, Zimbawe, Southern AFRICA, ejonathan@nust.ac.zw

\section{Abstract}

An optics laboratory plays a critical role in optics education. A major challenge for optics educators in Africa is the shortage or non-availability of laboratory teaching equipment. Optics teaching equipment is beyond the budget of most universities in the developing world such as the new National University of Science and Technology in Zimbabwe.

The paper details a successful strategy - local fabrication/assembling of optics laboratory teaching aids - adopted by the Applied Physics Department at Zimbabwe's National University of Science and Technology. Students and technical staff under the guidance of an academic member of staff do equipment fabrication and assembling.

The paper describes some of the project-type set-ups for performing experiments on (1) laser light scattering and impurity determination; (2) industrial imaging inspection (3) light transmission and reflection and (4) refractive index measurement.

\section{Keywords}

Applied physics, optics education, optics laboratory.

\section{Introduction}

\section{Summary}

The science of optics includes light emission, transmission, deflection, amplification and detection by optical components and instruments, lasers and other light sources, fibre optics, optical-electronics instrumentation, related hardware and electronics and sophisticated systems [1]. In recent years, optics has started to enjoy growing importance in a number of high technology activities such as energy generation, telecommunications, information technology, medical diagnostics and treatment, quality control, environment control, ranging and structure health monitoring [2-5].

In response to the growing importance of optics, education institutes across the globe including the National University of Science and Technology (NUST), a young tertiary institute in Zimbabwe tasked with producing scientifically and technologically literate graduates for careers in optics, now offer optics courses. The optics classes at NUST are part of a 4-year Bachelor of Science Honours in Applied Physics degree programme and a 2-year Master of Science in Lasers and Optics [6].

Optics education at NUST combines formal lectures and laboratory sessions. The objective of running optics laboratory sessions is provision of practical experience to supplement and illustrate concepts developed and discussed during formal lectures. A persistent challenge in realising this noble objective is how to fit within the available budget. The task is made more challenging by the fact that instead of offering laboratory 
classes to verify a concept, emphasis is also placed on stimulating students by going beyond merely confirming a formula or concept.

The realisation that laboratory teaching is a critical component of optics teaching if students are to be equipped with the necessary manual and mental skills for a future career in the optics industry has motivated an alternative approach towards equipping NUST for optics experiments within the available limited budget. The cost-effective remedy is offering mini project-type (1) experiments supported through local fabrication/assembling of components and devices and (2) experiments that use consumer-grade components and devices.

\section{Example experiments}

The motivating factors for local fabrication/assembling of optics experiments are-: (1) more educational value; (2) cost-effectiveness; (3) easy maintenance; and (4) easy duplication, upgrading or modification. The exercise involves academic staff members, technical staff members and students. Since the exercise is hands-on, other benefits in addition to improving laboratory teaching of optics include development and sharpening of local technical skills. Five sets of optics experiments have been developed this far as described in the following subsections.

\subsection{Laser Light Scattering and Impurity Determination}

The setup developed and is depicted in Figure 1a affords studying He-Ne laser (2mW) light scattering by different solutions and suspensions [7]. For a primary detection element, a light detection resistor (LDR) is used to detect scattered intensity normal to the incident beam optical axis at a laser-to-detector distance of $1000 \mathrm{~mm}$. Students have a choice of detecting LDR resistance as a direct indicator of scattered intensity or for those interested a sophisticated referenced detection scheme, for example a Wheatstone bridge [8], can be built around the LDR. The inserted Table 1 presents typical measurements with the system for different solutions. 
Table 1: Typical measurements using the system depicted in figure 1(a)

\begin{tabular}{|l|l|l|}
\hline SAMPLE & $\begin{array}{l}\text { FWHM } \\
\text { (mrad) }\end{array}$ & $\begin{array}{l}\text { Measured } \\
\text { Peak Intensity } \\
\text { (abu) }\end{array}$ \\
\hline $\begin{array}{l}\text { Direct Laser } \\
\text { Beam }\end{array}$ & 1.0 & 3600 \\
\hline $\begin{array}{l}\text { Glaa Test Tube } \\
\text { (Empty) }\end{array}$ & 4.99 & 1590 \\
\hline $\begin{array}{l}\text { Table Salt } \\
\text { (lodised) }\end{array}$ & 15.0 & 590 \\
\hline $\begin{array}{l}\text { Table Salt (non- } \\
\text { iodised) }\end{array}$ & 11.3 & 468 \\
\hline
\end{tabular}

Optical bench

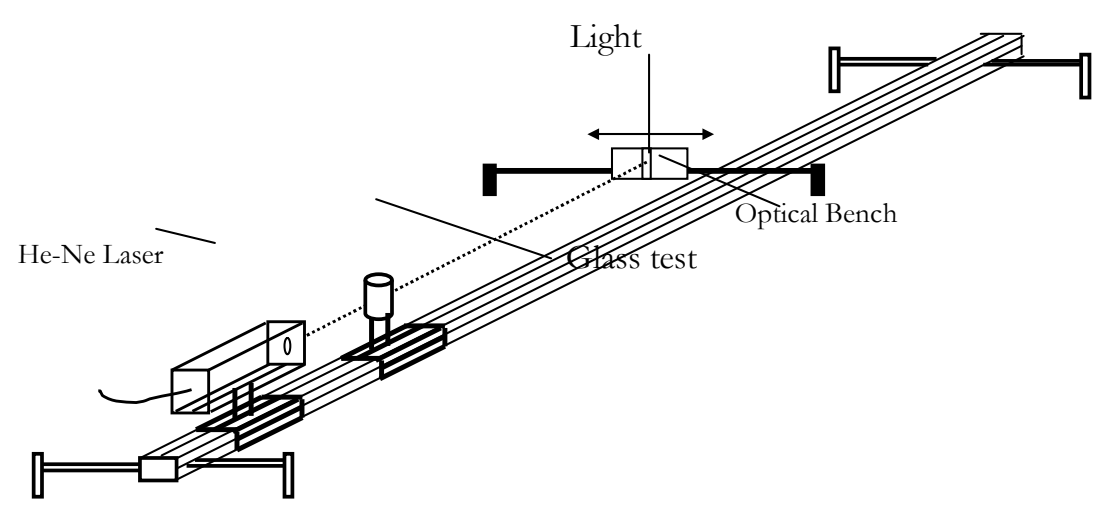

Figure 1: (a) Laser light scattering experiment set-up. Table 1 presents the typical response of the system. 


\subsection{Industrial Image Inspection}

The system (see Figure 2a) combines a laptop computer that drives a consumer-grade digital projector to produce structured light $[9,10]$ and for a 2-D imaging array a consumer-grade digital camera is used. Students are able to inspect objects with different surface profiles using the system. Figure $2 \mathrm{~b}$ presents some of the results obtained with the system.

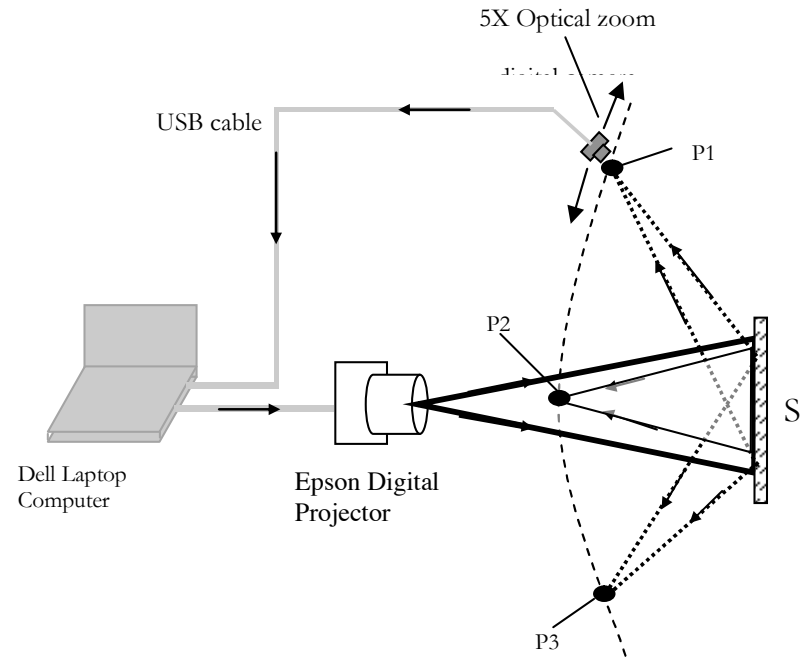

(a)

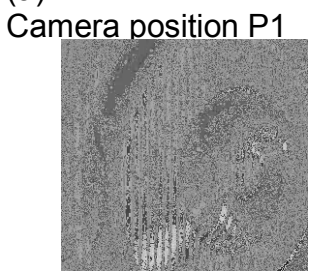

(i)

(b)

Figure 2: (a) Laboratory set-up for the industrial image inspection. Synthetic "fringes" are generated by the laptop computer and are projected onto the sample under investigation with a digital projector. Use of a laptop offers flexibility in choosing different illuminating patterns. (b) Typical results obtained with the system projecting vertical "fringes" shown as $b(i i)$. The sample under investigation is a locally manufactured plastic lid. Processed sample images $b(i)$ with the digital camera position marked $\mathrm{P} 1$ as indicated figure 2(a); and $b$ (ii) for camera position P3 marked on figure 2(a).

\section{Light transmission and reflection}

The objective of the experiment is to study the transmission and reflection of common optical wavelengths by selected optical thin films [11]. A vacuum thin film deposition device (device performance is shown in Figure 3a) procured from India is used to 
deposit metallic thin films of different thickness on selected substrates. The bench set-up is shown in Figure 3b. Figure $3 \mathrm{c}$ and $3 \mathrm{~d}$ illustrates typical experimental results.

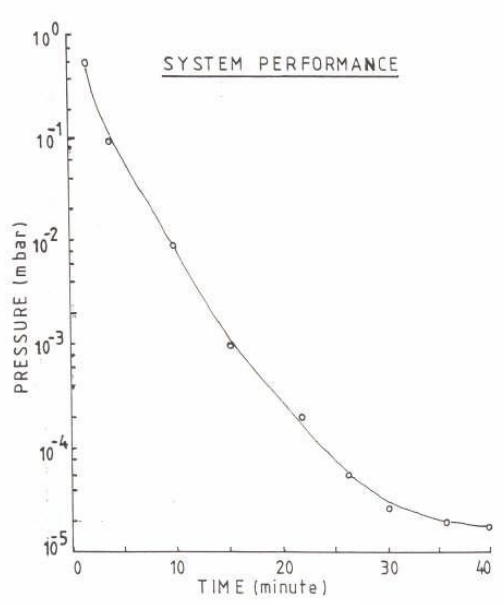

(a)

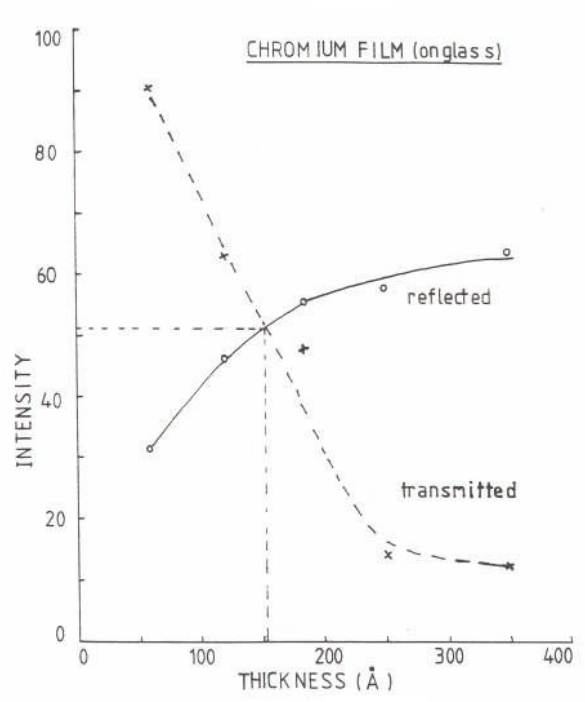

(c)

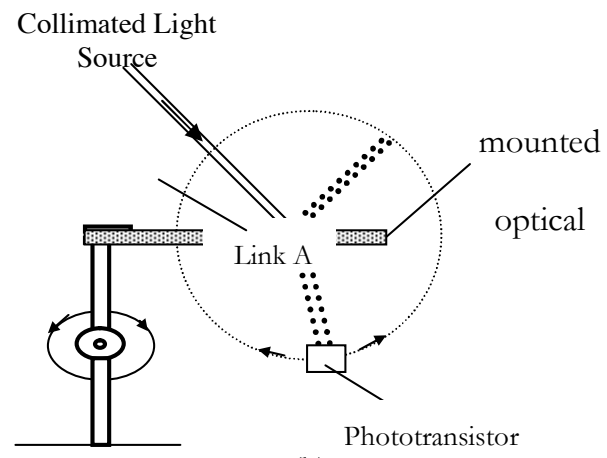

(b)

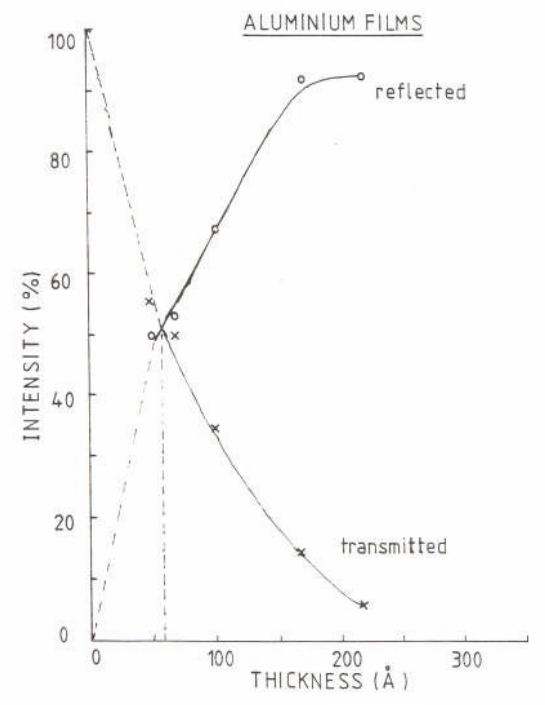

(d)

Figure 3: (a) Response of the vacuum coating unit. (b) Bench set-up. Link A permits varying the angle of incidence. Typical plots for (c) Chromium and (d) Aluminium film on glass. 


\section{Refractive Index Measurement}

The laboratory experiment is summarised schematically as Figure 4. Sample index of refraction is determined indirectly by measuring the angular shift of a particular spectral line caused by the sample with the glass prism at the Schuster position.

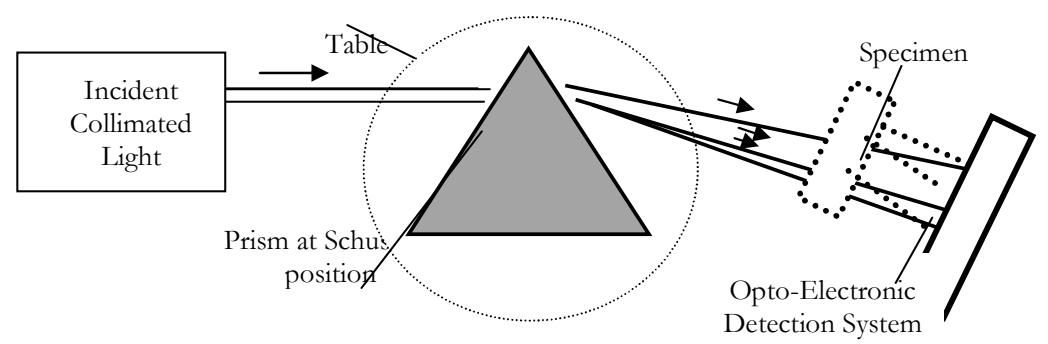

Figure 4: Schematic diagram of the laboratory set-up to determine refractive index 2.5 Other Experiments

Two minor experiments namely, determination of grating pitch using the phenomenon of self-imaging and determination of angle of wedge, have also been successfully developed through the strategy of local fabrication and assembling. 


\section{Conclusion}

Local fabrication and assembling of laboratory teaching equipment is a viable strategy of significantly improving optics education in developing countries. A recent trend is bulk optics is being replaced by fibre optics. Most of the research and development work in the area of photonics involves the use of optic fibre. We are planning to revisit our experimental set-ups to identify where in-fibre optics can be used. For example, the image inspection set-up in Figure 2a could be replaced by the configuration illustrated in Figure 5 depicting a fibre-based Young's double slit interferometer.

Apart from its technological importance, fibre optics provides an excellent opportunity to demonstrate a large number of physical concepts through simple experiments. It is planned to develop a fibre optics experiments kits for the Bachelors and Masters optics laboratory classes.

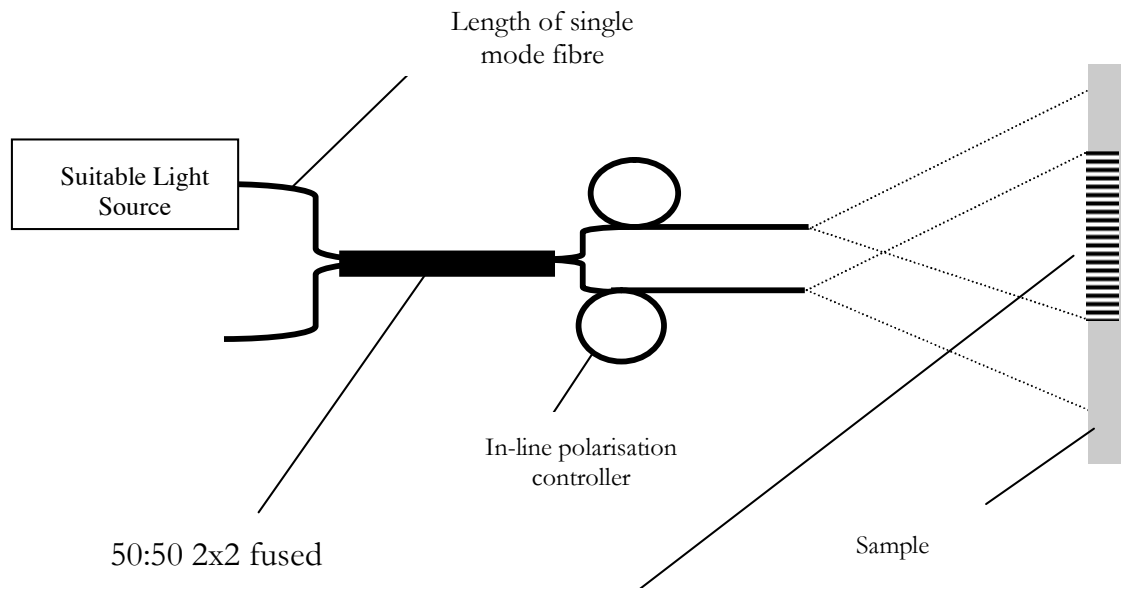

Resultant fringes

Figure 5: Fibre-based Young's Double Slit Configuration.

Today, computers continue to find their way into physics laboratories [12]. In our case, computers can be introduced as data acquisition and analysis devices. This will involve design and fabrication of computer interfacing boards and the development of appropriate data acquisition and analysis software preferably under Windows ${ }^{\circledR}$ environment. As part of better organisation of the optics laboratory class, experiment objective, equipment list, procedure, theory and simulations could also be hosted on the same computer.

\section{Acknowledgements}

The author thanks the National University of Science and Technology (NUST). Thanks are also due to the organisers of ETOP 2005 for offering the author the opportunity to present this work. 


\section{References}

[1] Lasers, principles and applications, Wilson \& Hawkes (Prentice Hall) ISBN 0-13523697-5.

[2] Andrew M Pakhomov, J. Phys. G: Nucl. Par. Phys. 28 (2002) 1469-1476

[3] http://www.fastcomtec.com/fwww/lidar/lidar.htm

[4] Sune Svanberg, "Laser spectroscopy in development," Europhysics News (2002) Vol. 33 No. 2.

[5] Karianne Pran et al (2000) Meas. Sci. Technol. 13 471-476.

[6] National University of Science and Technology YEARBOOK 2005

[7] Bohren, Craig F. / Clothiaux, Eugene E. Fundamentals of Atmospheric Radiation, (Wiley-VCH, Berlin) ISBN 3-527-40503-8.

[8] Ian Sinclair, Sensors and Transducers: A Guide for Technicians, (Newnes) ISBN 0750649321.

[9] Cheng, X.X., Su, X.Y., and Guo, L.R., Automated measurement method for 360 profilometry of diffuse objects, Applied Optics, 30(10), 1274-1278, 1991.

[10] Halioua, M., Krishnamoorthy, R.S., Liu, H. and Chiang, F.P., Automated 360 profilometry of 3-D diffuse objects, Applied optics, 24(14), 2193-2196, 1985.

[11] Kasturi L. Chopra, THIN FILM PHENOMENA McGraw-Hill, Inc., New York (1969). 